\title{
Context and Companionship in Children's Short-term versus Long-term Friendships
}

\author{
By: David R. Troutman, Anne C. Fletcher
}

Troutman, D. R., \& Fletcher, A. C. (2010). Context and Companionship in Children's Short-term versus Long-term Friendships. Journal of Social and Personal Relationships, 27(8), 1060-1074. doi: $10.1177 / 0265407510381253$

Made available courtesy of Sage Publications: http://www.dx.doi.org/10.1177/0265407510381253

\begin{abstract}
***Reprinted with permission. No further reproduction is authorized without written permission from Sage Publications. This version of the document is not the version of record. Figures and/or pictures may be missing from this format of the document. ***
\end{abstract}

\begin{abstract}
:
Children $(N=341)$ and their mothers participated in interviews when children were in fourth and fifth grades. Mothers and children worked together to identify children's friends across various contexts of their lives. Children rated the companionship of each friendship and friendships were coded as either short term or long term. Higher levels of companionship were associated with increased odds of a friendship being long term, as was a friendship being maintained within the contexts of neighborhood, family friend, relative-as-friend, and efforts of parents. A friendship being maintained in more contexts was associated with increased odds of the friendship being long term. The findings are discussed in terms of implications for the understanding and support of children's friendships.
\end{abstract}

Keywords: children | stability | companionship | context | friendship | parental influence

\section{Article:}

Friendships provide children with opportunities to negotiate intimate social relationships characterized by egalitarian interactions (Bigelow, Tesson, \& Lewko, 1999) and the choice to maintain or terminate relationships (Rubin, Bukowski, \& Parker, 1998). Children's long-term friendships are likely particularly meaningful, providing opportunities for intimate exchanges over time. Limited research (e.g., Bukowski, Hoza, \& Boivin, 1994) has focused on how friendships may differ depending on their duration. This research focuses on identifying those factors (i.e., characteristics of friendships and their environment) associated with the longevity of children's friendships. Specifically, we contrast long- and short-term friendships on the extent to which they are characterized by companionship and maintained within different contexts of children's lives.

\section{Process-Person-Context-Time model}

The current study is framed by Bronfenbrenner's Process-Person-Context-Time (PPCT) model (Bronfenbrenner, 1986, 2004; Bronfenbrenner \& Morris, 1998). In this model, individual 
development is shaped by interactions among individuals (process), characteristics of individuals (person), the contexts in which development occurs (context), and continuity and change over time (time). This model fits the present investigation because children's friendships are dynamic as they are maintained over time and within multiple contexts. They also reflect characteristics of both partners (e.g., aggressive tendencies; Cillessin, Jiang, West, \& Laszkowski, 2005) and interactions between these partners (e.g., conflict; Burk \& Laursen, 2005). Thus, including multiple variables from the PPCT model should enhance understanding of children's friendships. Specifically, we examine whether children's reports of friendship companionship (process) and friendship context (e.g., school, neighborhood, child care) differentiate short-term and long-term friendships (time).

\section{Friendship stability}

Research on friendship stability typically involves a prospective approach, considering whether friendships present at one point in time are also present at a later point (e.g., Ladd, Kochendehfer, \& Coleman, 1996). In contrast, the present study considers friendship stability in terms of whether existing friendships have been maintained for shorter, as opposed to longer, periods of time (a retrospective approach). These different conceptualizations of the duration of children's friendships provide unique views of children's friendships, each with its unique strengths and weaknesses. A prospective approach ignores friendship duration prior to dissolution, but captures important information on whether friendships remain intact. Focusing on "new" versus “old” ' friendships (a retrospective approach) is unable to differentiate friendships that will, versus will not, continue over time, but may be informative concerning the reality of friendship maintenance patterns.

With notable exceptions (e.g., Berndt \& Hoyle, 1985; Ladd et al., 1996), few empirical works have used the retrospective approach. This work suggests that children's friendships in late childhood and early adolescence are relatively short lived. Neckerman (1996) found that over one year, children's school-based friendships were particularly unlikely to remain intact when schools did not move promoted children in intact classes to the next grade. Cairns, Leung, and Cairns (1995) reported that across three weeks, three in 10 of early adolescents' social network members changed and, over one year, only $16 \%$ of social networks remained identifiable.

Other work suggests greater stability in friendships. Ladd et al. (1996) reported that 50 out of 82 children maintained at least one (out of five) stable friendships from January to May; however, they did not report instability rates. Berndt and Hoyle (1985) reported that between half and three-quarters of elementary school children's within-classroom friendships were stable across one school year. It is noteworthy that these studies investigated within-classroom friendship stability during the school year. In this developmental period, children's friendships are likely to be unstable because interactions are limited in the school setting. Therefore, we suspect that whether friendships have been maintained for more or less than one year is a meaningful distinction.

\section{Companionship and friendship length}


When identifying factors that may differentiate short-term from long-term friendships, we first considered characteristics indicative of the quality of friendships, such as friendship companionship. Friendship companionship represents the amount and quality of time children spend together (Parker \& Asher, 1993) and varies systematically by individual and friendship characteristics. Children who engage in more prosocial behavior (Cillessin et al., 2005) and who are lower in social anxiety (La Greca \& Lopez, 1998) tend to have more companionable friendships, Higher levels of companionship are present within friendships lower in relational aggression (Cillessin et al., 2005) and competition (Schneider, Woodburn, del Pilar Soteras del Toro, \& Udvari, 2005). Children with greater friendship companionship are less likely to experience peer victimization (Malcolm, Jensen-Campbell, Rex-Lear, \& Waldrip, 2006).

Companionship is also related to the maintenance of friendships over time. Companionship is higher in best friend (than non-best friend) dyads (Cleary, Ray, LoBello, \& Zachar, 2002), even within classrooms (Meurling, Ray, \& LoBello, 1999). Best friendships stable over six months exhibit more companionship than unstable best friendships (Bukowski et al., 1994). Taken together, these findings suggest that long-term friendships should contain more companionship than short-term friendships. Research investigating companionship over time in friendships has focused primarily on best friendships. Methodological and statistical challenges associated with analyzing nested data involving children with multiple friends have precluded consideration of how companionship relates to friendship longevity. The current study uses Hierarchical Generalized Linear Modeling (HGLM), specifically designed for analyzing nested data, allowing us to address such questions.

\section{Friendship context and duration}

The contexts within which children's friendships are created and maintained may differentiate short-term from long-term friendships. Knowledge of how context shapes friendships is limited, as past studies have generally been performed only in school settings. Children's friendships during late childhood occur within seven contexts: school, neighborhood, church, child care, family friend (children of parents' friends), same-age relative, and extracurricular activities (Fletcher, Troutman, Gruber, Long, \& Hunter, 2006b). The term context here refers to sources of friendships and included both physical settings (e.g., schools, churches) and relational characteristics (e.g., same-age relatives). Such a definition suggests that friendships can be maintained across multiple contexts and may be linked to parent-to-parent relationships (e.g., within neighborhood and church).

Context may influence both interparental and children's social relationships. One strong predictor of friendship formation and maintenance is physical proximity (Epstein, 1983). The longevity of friendships may be influenced by children's social environments (Berndt \& Hoyle, 1985). Schools that preserve classroom unity from year to year generate longer-term schoolbased friendships (Neckerman, 1996). Given the small amount of research conducted outside of school, we know virtually nothing about how other contexts relate to friendship duration.

Parents influence their children's friendships both directly and indirectly (Parke \& Ladd, 1992), particularly during late childhood (Franco \& Levitt, 1998). Children have increased chances to interact and friendships may persist when both partners' parents are themselves friends or 
acquaintances. Thus, friendships maintained in contexts containing both children's parents (family friend, same-age relative, neighborhood, and church) are more likely to be long term. Friendships in contexts not including parents (school, child care, and extracurricular activities) likely decrease the likelihood that a friendship will be long term. Although no work has examined associations between friendship contextual variety and friendship duration, work focusing on the number of friendship contexts and interparental relationships (Fletcher et al., 2006b) suggests that more contexts increases the odds that a friendship will be long term.

\section{Friendship context, companionship, and duration}

Disruptions that characterize some contexts are likely to decrease the strength of relationship between companionship and friendship length. There is likely a positive association between friendship companionship and friendship length, yet unstable contexts (e.g., school, child care, and possibly extracurricular activities) may attenuate this relationship. For example, children with close and companionable school friendships may find it difficult to maintain these friendships over time, due to factors such as extended time that school friends spend apart (e.g., summer vacation) and assignments to new classrooms each year. Therefore, the school context may reduce the impact of friendship companionship on friendship maintenance over time.

In contrast, relatively stable contexts likely allow friendship companionship to facilitate longterm friendship. Parents play a critical role in providing regular opportunities for interaction. Parents' abilities to provide interaction opportunities are likely to be greater in contexts that include parents (e.g., church, neighborhood, family friends, same-age relative). Thus, friendships within such contexts are likely to generate stable friendships characterized by a stronger association between companionship and friendship length.

Research on both friendship companionship and children's friendship length has rarely focused on ethnic differences or how ethnicity might moderate associations between these constructs and other variables. Our past research (Fletcher, Hunter, \& Eanes, 2006a) indicated considerable ethnic and social class differences in the likelihood that a friendship will be maintained within a given context. Accordingly, we elected to control for ethnicity and social class in focal analyses.

\section{Hypotheses}

Given our theoretical and empirical background, we pose the following questions. First, does the likelihood of long-term friendships vary across contexts? We hypothesize that friendships maintained in parentally based contexts (i.e., parent network, same-age relative, church, and neighborhood) are more likely to be long term than friendships maintained in non-parental contexts (i.e., school, child care, extracurricular activities). Second, we consider the relationship between companionship and friendship duration and whether such an association is moderated by context. We hypothesize that strong friendship companionship will be associated with increased likelihood of children's long-term friendships. Moreover, this relation will be stronger with parent-based contexts (i.e., parent network, same-age relative, neighborhood, church) than in non-parent-based contexts (i.e., school, child care, extracurricular activities). Third, we consider whether the number of contexts within which friendships were maintained would increase the likelihood that friendships would be long term and whether context moderates this 
relationship. We hypothesize that friendships maintained in multiple contexts are more likely to be long term. Moreover, the association between friendship companionship and friendship duration will be stronger when friendships are maintained across multiple contexts. No hypotheses were offered with respect to ethnic or social class variations in length of friendship, given the lack of existing research relevant to this focus.

\section{Methods}

\section{Participants}

The participants, drawn from two waves of a short-term longitudinal study of children's friendships and well-being conducted in a single county (with rural, urban, and suburban areas) in the southeastern portion of the United States, included 341 children and their mothers. Children (53\% girls) were enrolled in fourth grade during the first wave and fifth grade during the second (mean child age $1 / 410.34$ years, range $1 / 4$ 9-12, SD $1 / 40.53$ years). The sample was 39\% Black and 61\% White. Using Hollingshead's (1975) measure, mean socioeconomic status (SES) scores were 43.67 (medium business personnel and minor professional's SD 1/4 11.52) and ranged from 15 (unskilled laborers) to 66 (major business professionals).

\section{Measures}

Demographics. Demographic data were collected in a family roster interview with mothers in wave 1 . Mothers reported family members' ethnicity (Black $1 / 40$, White $1 / 41$ ) and child gender (Female $1 / 4$ 0, Male $1 / 41$ )). Mothers also reported educational levels and occupations for themselves and target children's fathers (if mothers considered them to play an active role in children's lives) to calculate the SES measure.

Children's friendships and contexts. During waves 1 and 2, mothers and children completed the Social Contexts of Friendships (SCF) interview together. This interview yields a list of no more than 10 same-age non-sibling children both dyad members consider to be target children's friends, as well as information about each friendship, including the context(s) in which the friendship is maintained. Asking mothers and children to generate the friendship list together results in a more accurate list of children's friendships than is generated by children or mothers alone (Fletcher, Troutman, Madison, \& Hunter, 2010). Children maintained friendships in school, neighborhood, church, child care, extracurricular activities, children of family friends, and relatives as friends, and "other efforts"' (friendships initially established within contexts such as school, neighborhood, or child care, but since children no longer occupied these contexts these friendships were maintained by other efforts such as telephone calls, email, and home visits). Each friendship was coded for each wave 1 context ( 0 1/4 not maintained; 1 1/4 maintained) as well as the total number of wave 1 contexts.

Friendship length. Given measurement constraints, we defined friendship length retrospectively and dichotomously as short term (friendships identified only at wave 2, coded as 0 ) or long term (the same friend nominated at both waves 1 and 2, coded as 1).

Friendship companionship. Children completed the companionship subscale of the Friendship 
Qualities Scale (four items; Bukowski et al., 1994) for each friend (e.g., "Sometimes my friend and I just sit around and talk about things like school, sports, and things we like’'). At wave 2, children were asked to "rate friendships according to the way it is now and not how you want it to be’. Response options range from 1 (not at all true) to 5 (really true) (a1/4.72).

\section{Procedure}

Parents with third-grade children enrolled in nine elementary schools during the 2001-2002 school year were asked to participate in a school-based data collection. Criteria for participation in subsequent home-based interviews included White or Black ethnicity (the two most prevalent ethnic groups within the region), children residing with biological or adoptive mothers (as mothers are more likely to be responsible for the day-to-day care and supervision of children; Helms \& Demo, 2005; Lareau, 2000), children born in the US, and participation in the schoolbased project. Mothers were contacted by telephone and asked to participate in initial interviews. Four hundred and four families (79\% of eligible families) agreed to participate in initial interviews. Wave 1 interviews were conducted during target children's fourth grade school year and wave 2 interviews during fifth grade.

Interviews took place in participants' homes or at a location of participants' choosing (e.g., a university research laboratory), were conducted by two research assistants, and took approximately 75 minutes. Except for the SCF, mothers and children completed questionnaires and answered interview questions separately. Demographic data were gathered first, followed by the SCF interview, and then the companionship measure. Questionnaire items were read aloud to children and were read aloud to mothers if they appeared to have difficulty completing questionnaires. Mothers received \$35 for their participation and children received small gifts. To minimize attrition, families moving to a different region of the country between waves of data collection were asked to complete interviews by telephone and to complete mail-in questionnaires (fewer than $2 \%$ of cases). Mothers signed consent forms for their own and their children's participation and children provided oral assent.

\section{Results}

\section{Contexts of children's friendships}

At wave 2, the number of child friendships ranged from one to ten friends for a total of 2179 friendships (M 1/4 6.42; SD 1/4 2.34). Children's friendships were maintained across all eight contexts. Specifically, 64\% of friends were from schools, $23 \%$ neighborhoods, $20 \%$ extracurricular, $10 \%$ churches, $7 \%$ parent's friendships, $7 \%$ same-age relatives, $3 \%$ child care settings, and 7\% " other efforts." One-third (34\%; $n$ 1/4 731) of friendships were maintained across multiple contexts, mostly (89\%; $n$ 1/4 650) maintained both in school and at least one other context.

Friendships were evenly divided between short term (50.3\%) and long term. There were no significant differences in the average number of long-term versus short-term friendships nominated within each context. Mean levels of friendship companionship did not differ for shortterm and long-term friendships within each context. 


\section{Analytic strategy}

Data were analyzed using two-level HGLM predicting length of friendship, a dichotomous outcome variable (Raudenbush \& Bryk, 2002). Friendships were the level 1 (within) factor and children the level 2 (between) factor. HGLM regressions at level 1 use level 1 (within factor) intercepts and slopes as level 2 dependent variables.

We constructed three types of level 1 equations. The first predicted friendship length from companionship and contexts entered simultaneously. For example, in equation (1a), Zij is the dichotomous friendship length indicator ( $01 / 4$ short-term, $1 \frac{1}{4}$ long-term) for observation $i$ in group $\mathrm{j}$ (Tate, 2004). b0j represents the intercept of the regression equation for group $\mathrm{j}$ and $\mathrm{b} 1 \mathrm{j}$ through b9j represent the main effects of variables entered. The effect of friendships being maintained across multiple contexts is controlled for by placing all contexts in the level 1 equation. Friendship context variables were dichotomously coded ( 0 if the context was not used and 1 if it was). In contrast, companionship was a continuous predictor variable.

Level 1 equation:

$$
\begin{aligned}
& \text { Logit } \eta_{i j} \text { (Length of friendship) }=\beta_{0 j}+\beta_{1 j} \text { companionship }{ }_{1 i j}+\beta_{2 j} \text { school }{ }_{2 i j} \\
& +\beta_{3 j} \text { neighborhood }{ }_{3 j}+\beta_{4 j} \text { church }_{4 i j}+\beta_{5 j} \text { childcare }_{5 i j} \\
& +\beta_{6 j} \text { parent network } 6 j+\beta_{7 j} \text { relative }_{7 j} \\
& +\beta_{8 j} \text { extracurricular } r_{8 j}+\beta_{9 j} \text { other effort } t_{9 j}
\end{aligned}
$$

The second type of level 1 equation (e.g., equation (1b)) predicted length of friendship from a continuous measure of number of contexts. To examine how number of contexts might moderate the association between companionship and friendship length, b0j - represents the intercept of the regression equation for group $\mathrm{j}$ and $\mathrm{b} 1 \mathrm{j}$ and $\mathrm{b} 3 \mathrm{j}$ the main effects of the variables listed. As suggested by Aiken and West (1991), b3j is the interaction term created by mean centering the companionship variable, then multiplying the value by the number of contexts in which friendships were maintained. All variables in the HGLM equation are grand mean centered.

Level 1 equation:

$$
\begin{aligned}
\text { Logit } \eta_{i j} \text { (length of friendship) }= & \beta_{0 j}+\beta_{1 j} \text { companionship } p_{1 j j}+\beta_{2 j} \text { number of contexts }{ }_{2 j} \\
& +\beta_{3 j} \text { companionship }_{1 i j} \times \text { number of contexts }_{2 i j}
\end{aligned}
$$

The third type of level 1 equation (see equation (1c)) identified specific contexts as moderators of associations between companionship and friendship length. A series of level 1 equations were constructed, each including an interaction term with a single context. To create these interaction terms, the companionship variable was mean centered, then multiplied by one of the eight context variables individually. For example, b10j is the within-level interaction between companionship and school context. Eight level 1 equations, one unique interaction term for each context, were created.

Sample Level 1 equation (for the moderating effect of school context): 
Logit $\eta_{i j}$ (Iength of frienship) $=\boldsymbol{\beta}_{0 j}+\boldsymbol{\beta}_{1 j}$ companionship $p_{1 j j}+\beta_{2 j}$ school $_{2 j}$

$$
\begin{aligned}
& +\beta_{3 j} \text { neighborhood }_{3 i j}+\beta_{4 j} \text { church }_{4 i j}+\beta_{5 j} \text { childeare }_{s i j} \\
& +\beta_{6 j} \text { parent network }_{6 i j}+\beta_{7 j} \text { relative }_{7 i j} \\
& +\beta_{8 j} \text { extracurricular }_{8 i j}+\beta_{9 j} \text { other effort } \\
& +\beta_{10 j} \text { companionship }_{1 i j} \times \text { school }_{2 i j}
\end{aligned}
$$

In level 2 equations (see equation (2)), two child-level predictors (SES and ethnicity) were included as control variables. Equation (2) corresponds to equation (1a), where g00 is the grand mean intercept of friendship length across groups, g01 is the main effect for SES, and g02 is the main effect for ethnicity; u0j through u9j represents the residual variance; g10 through g90 denote the main effect for companionship and specific contexts (e.g., school, neighborhood, etc.):

$$
\begin{aligned}
& \beta_{0 j}=\gamma_{00}+\gamma_{01} \text { SES }+\gamma_{02} \text { ethnicity }+u_{0 j} \\
& \beta_{1 j}=\gamma_{10}+\gamma_{11} \text { SES }+\gamma_{12} \text { ethnicity }+u_{1 j} \\
& \beta_{2 j}=\gamma_{20}+\gamma_{21} \text { SES }+\gamma_{22} \text { ethnicity }+u_{2 j} \\
& \beta_{3 j}=\gamma_{30}+\gamma_{31} \text { SES }+\gamma_{32} \text { ethnicity }+u_{3 j} \\
& \beta_{4 j}=\gamma_{40}+\gamma_{41} \text { SES }+\gamma_{42} \text { ethnicity }+u_{4 j} \\
& \beta_{5 j}=\gamma_{50}+\gamma_{51} \text { SES }+\gamma_{52} \text { ethnicity }+u_{5 j} \\
& \beta_{6 j}=\gamma_{60}+\gamma_{61} \text { SES }+\gamma_{62} \text { ethnicity }+u_{6 j} \\
& \beta_{7 j}=\gamma_{70}+\gamma_{71} \text { SES }+\gamma_{72} \text { ethnicity }+u_{7 j} \\
& \beta_{8 j}=\gamma_{80}+\gamma_{81} \text { SES }+\gamma_{82} \text { ethnicity }+u_{8 j} \\
& \beta_{9 j}=\gamma_{90}+\gamma_{91} \text { SES }+\gamma_{92} \text { ethnicity }+u_{9 j}
\end{aligned}
$$

Similar level 2 equations were constructed to correspond to equations (1b) and (1c).

Child-level predictors of length of friendship. Based on equations (1a) and (2), Ethnicity was a significant and positive predictor of friendship length (g $1 / 4.50$, standard error (SE) $1 / 4.13$, $t$ [338] $1 / 43.81, \mathrm{p}<.01$ ), indicating that the odds of a White child having a long term friendship were 1.65 times greater for White children as compared to Black children. In addition, SES was a significant and positive predictor of friendship length (g 1/4 .01, SE 1/4 .01, t[338] 1/4 2.02, p <.05), indicating the odds of a friendship being long term increased by 1.01 for one standard deviation increase in SES.

Number of contexts and friendship length. Equation (1b) and (2) examined the number of contexts as a predictor of length of friendship. As hypothesized, the number of contexts was a significant and positive predictor of length of friendship, $\left(g^{1 / 4.22, ~ S E 1 / 4.13, ~} t(338)^{1 / 4} 3.81, \mathrm{p}<.01\right.$; odds ratio $1 \frac{1}{4} 1.25$ ), holding all other variables constant.

Context as moderator. Eight HGLM models based on equations (1c) and (2) considered whether contexts moderated the association between companionship and length of friendship. Each 
HGLM model examined a single interaction term using one context and friendship companionship. None of the interactions were statistically significant. In other words, specific friendships contexts did not moderate the association between friendship companionship and length of friendship.

Equations (1b) and (2) also considered whether number of contexts moderated the association between companionship and length of friendship. Inconsistent with our hypothesis, the regression coefficient was not significant, indicating that number of contexts did not moderate the association between friendship companionship and length of friendship.

\section{Discussion}

Most previous research on children's friendships focused on the school context and ignored the temporal nature of such relationships. In contrast, the current study considered the roles of friendship companionship and friendship context in determining whether a friendship would be short term or long term. Long-term friendships were characterized by higher levels of companionship and contexts that include both children and parents (i.e., neighborhood, family friend, relative-as-friend, friendships maintained through the efforts of parents). Contrary to predictions, context did not moderate the relationship between companionship and friendship length.

Using analyses that considered the nested nature of children's friendships, whether a friendship was short term or long term varied as a function of both specific context(s) and the number of contexts across which it was maintained. Friendships maintained within parent-related contexts were more likely to be long term, includes family friends, same age relatives, neighborhood friendships, and the instances in which parents helped maintain friendships that had developed in another context. Such contexts represent intersections between family and peer microsystems - a mesosystem influence (Bronfenbrenner, 2004). In all likelihood, such points of connection allow parents increased opportunities to behave in ways that support the maintenance of children's friendships. For example, parents may provide children with additional opportunities to interact with friends (Rubin et al., 1998) and/or monitor their children's social relationships and interactions (Knoester, Haynie, \& Stephens, 2006).

Coleman (1988) referred to children's friendships that were characterized by social relationships among parents as being high in social network or intergenerational closure and posited benefits to children when strong connections existed between parents. Fletcher and colleagues (Fletcher et al., 2006a,b) described a number of mechanisms that might account for links between closure relationships and the maintenance of children's friendships over time. For example, children whose parents know one another have additional adult resources to draw upon when conflicts occur between children or when children wish to schedule play dates and sleepovers. Parents may anticipate opportunities to socialize with adult friends while their children are interacting. In summary, the longevity of children's friendships within parental contexts may be a function of contact frequency and shared relational histories.

Our finding that greater companionship increased the likelihood of long-term friendships extends earlier work (Bukowski et al., 1994; Cleary et al., 2002; Meurling et al., 1999) by implicating 
companionship as a factor differentiating short- and long-term friendships - regardless of whether the relationships are "best" friendships. Measuring companionship only once leaves two explanations for this association. First, without interactions that facilitate companionship, friendships are likely to dissolve. Second, levels of companionship likely increase over time in long-term friendships. Our findings and other research suggest that both processes are probably at work. Hays (1985) noted that interactions within young adult friendships increased in frequency over time. Hardy, Bukowski, \& Sippola (2002) reported that when friends experience low companionship, motivation to maintain relationships likely declines, leading to friendship termination.

We found that one-third of children's friendships were maintained across multiple (and as many as five) contexts. Consistent with bioecological theory, multiple contexts increased the odds of long-term friendships, likely because they provide exposure to the proximal processes (friendship interactions) that contribute to friendship longevity. Maintaining friendships across multiple contexts provides children with increased opportunities to interact in different situations and for longer periods of time. Maintaining friendships across multiple contexts may also promote friendship longevity, because terminating one context (e.g., soccer season ends) does not end chances to interact.

Both ethnicity and social class predicted friendship length in that White (and more affluent) children reported more long-term friendships than Black (and less affluent) children. Our own work (Fletcher, Bridges, \& Hunter, 2007) suggested that Black mothers are more cautious than White mothers in encouraging their children to connect with friends outside of school. Although Black families may be very flexible in defining and maintaining relationships with family and close family friends (Hunter \& Taylor, 1998; Johnson, 2000), they may be more guarded against other " "external” relationships. Parents raising children in high-crime or disordered neighborhoods (more likely economically disadvantaged) may restrict children’s social relationships to keep them safe (Furstenberg, Cook, Eccles, Elder, \& Sameroff, 1999). Such strategies may keep children safe, but likely make it more difficult for children to maintain friendships over time.

We were surprised that the relationship between companionship and friendship length was not moderated by either specific contexts or the number of contexts. While both companionship and contexts independently influence friendship length, these influences appear additive rather than interactive. Friendships are more likely to continue when children spend more time engaged in positive interactions no matter what the context.

Considerable research indicates that greater companionship within friendships is linked with a variety of positive individual and dyadic characteristics, such as increased prosocial behavior (Cillessin et al., 2005) decreased social anxiety (La Greca \& Lopez, 1998), relational aggression (Cillessin et al., 2005), competition (Schneider et al., 2005), and victimization (Malcolm et al., 2006). Our results suggest that building friendships high in companionship may also help children to sustain long-term friendships. Furthermore, long-term friendships are particularly likely when children's parents are present. 
Therefore, concrete strategies can be implemented by both children and parents to support longterm child friendships. Specifically, long-term friendships are more likely when friendships are high in companionship, maintained across multiple contexts, and characterized by connectedness between the respective parents.

\section{Limitations and directions for future research}

The current study extended existing research on children's friendships by considering both relational and contextual factors that influence relationship longevity. Despite their importance, these findings are not without limitations. First, our strategy to identify children's friendships used the collaborative efforts of mothers and children to identify children's friendships. The "gold standard" in modern friendship research is reciprocal friendship nominations. Our approach cannot capture reciprocity. Individuals nominated by mother/child dyads may, to an extent, reflect desired (or desirable), rather than actual, friends. The advantage of our approach is that it identified friendships in contexts beyond school, the virtually exclusive context utilized used in previous studies. Future research should examine short- versus long-term friendships using diverse nomination criteria. Our sample included children in a single county in the southeastern US and was restricted to Black and White children. We cannot, with certainty, generalize our findings to other regions, countries, or ethnic groups. Further research on this topic should use both random and non-random sampling strategies and consider predictors of friendship length within samples diverse on a variety of demographic variables. Our study was limited to two points in time and the availability of companionship data at only the latter point. Such limitations forced us to adopt a simple, dichotomous, definition of friendship length. Future efforts should use multiple data points, allowing time series analyses to describe the progression of children's friendships. Despite these limitations, these findings represent an important advance in knowledge of children's friendships during late childhood. Children's friendships are complex, and traditional efforts to understand them have generated oversimplified pictures of this relationship. Friendship researchers should use methods that consider how children's friendships extend across time and context, and how friendships come to be nested within children. It is only by adopting conceptual and statistical approaches that explicitly acknowledge the complexity of children's friendship experiences that we can fully understand late children's social connectedness.

\section{Acknowledgement}

Duncan Cramer served as Action Editor for this article.

\section{Conflict of interest statement}

The author(s) declared no conflicts of interest with respect to the authorship and/or publication of this article.

\section{Funding}

This research was supported by a grant to Anne C. Fletcher and Andrea G. Hunter by the William T. Grant Foundation. 


\section{References}

Aiken, L. S., \& West, S. G. (1991). Multiple regression: Testing and interpreting interactions. Thousand Oaks, CA: Sage.

Berndt, T. J., \& Hoyle, S. G. (1985). Stability and change in childhood and adolescent friendships. Developmental Psychology, 21, 1007-1015.

Bigelow, B. J., Tesson, G., \& Lewko, J. H. (1999). The contextual influences of sibling and dating relations on adolescents' personal relations and their close friends, dating partners, and parents: The Sullivan-Piaget-Hartup hypothesis reconsidered. In J. A. McLellan \& M. V. Pugh (Eds.), New directions for child and adolescent development: Vol. 84. The role of peer groups in adolescent social identity: Exploring the importance of stability and change (pp. 71-86). San Francisco, CA: Jossey-Bass.

Bronfenbrenner, U. (1986). Recent advances in research on the ecology of human development. In R. K. Silbereisen, K. Eyferth, \& G. Rudinger (Eds.), Development as action in context: Problem behavior and normal youth development (pp. 286-309). New York: Springer.

Bronfenbrenner, U. (2004) Making human beings human: Bioecological perspective on human development. Thousand Oaks, CA: Sage.

Bronfenbrenner, U., \& Morris, P. A. (1998). The ecology of developmental processes. In R. M. Lerner (Ed.), Handbook of child psychology (5th ed., Vol. 1, pp. 993-1028). New York: Wiley.

Bukowski, W. M., Hoza, B., \& Boivin, M. (1994). Measuring friendship quality during pre- and early adolescence: The development and psychometric properties of the friendship qualities scales. Journal of Social and Personal Relationships, 11, 471-484.

Burk, W. J., \& Laursen, B. (2005). Adolescent perceptions of friendship and their associations with individual adjustment. International Journal of Behavioral Development, 29, 156-164.

Cairns, R. B., Leung, M.-C., \& Cairns, B. D. (1995). Social networks over time and space in adolescence. In L. J. Crockett \& A. C. Crouter (Eds.), Pathways through adolescence: Individual development in relation to social contexts (pp. 35-56). Hillsdale, NJ: Erlbaum.

Cillessin, A. H. N., Jiang, X. L., West, T. V., \& Laszkowski, D. K. (2005). Predictors of dyadic friendship quality in adolescence. International Journal of Behavioral Development, 29, 165-172.

Cleary, D. J., Ray, G. E., LoBello, S. G., \& Zachar, P. (2002). Children’s perceptions of close peer relationships: Quality, congruence, and meta-perceptions. Child Study Journal, 32, 179-192. 
Coleman, J. S. (1988). Social capital in the creation of human capital. American Journal of Sociology, 94, 95-120.

Epstein, J. (1983). Selection of friends indifferently organized schools and classrooms. In J. Epstein \& N. Kaxweit (Eds.), Friends in school: Patterns of selection and influence in secondary schools (pp. 73-92). New York: Academic Press.

Fletcher, A. C., Bridges, T., \& Hunter, A. G. (2007). Managing children's friendships through interparental relationships: Roles of ethnicity and friendship context. Journal of Marriage and Families, 69, 1135-1149.

Fletcher, A. C., Hunter, A. G., \& Eanes, A. Y. (2006a). Links between social network closure and child well-being: The organizing role of friendship context. Developmental Psychology, 42, 1057-1068.

Fletcher, A. C., Rollins, A., \& Nickerson, P. (2004). The extension of school-based inter- and intraracial children's friendships: Influences on psychosocial well-being. American Journal of Orthopsychiatry, 74, 272-285.

Fletcher, A. C., Troutman, D. R., Gruber, K., Long, E., \& Hunter, A. G. (2006b). Context and closure in children's friendships: prevalence and demographic variation. Journal of Social and Personal Relationships, 23, 609-627.

Fletcher, A. C., Troutman, D. R., Madison, K., \& Hunter, A. G. (2010). Identifying children's friendships across diverse contexts: The social contexts of friendships measure. Manuscript under review.

Franco, N., \& Levitt, M. J. (1998). The social ecology of middle childhood: Family support, friendship quality, and self-esteem. Family Relations, 47, 315-321.

Furstenberg, F. F., Cook, T. D., Eccles, J., Elder, G. H., \& Sameroff, A. (1999). Managing to make it: Urban families and adolescent success. Chicago, IL: The University of Chicago Press.

Hardy, C. L., Bukowski, W. M., \& Sippola, L. K. (2002). Stability and change in peer relationships during the transition to middle-level school. Journal of Early Adolescence, 22, 117142.

Hays, R. B. (1985). A longitudinal study of friendship development. Journal of Personality and Social Psychology, 48, 909-924.

Helms, H. M., \& Demo, D. H. (2005). Everyday hassles and family stress. In P. C. McKenry \& J. Price (Eds.), Families and change: Coping with stressful events and transitions (3rd ed., pp. 355-378). Thousand Oaks, CA: Sage.

Hollingshead, A. (1975). Four factor index of social status. Unpublished manuscript, Yale 
University.

Hunter, A. G., \& Taylor, R. T. (1998). Grandparenthood in African American families. In M. Szinovacz (Ed.), Handbook on grandparenthood (pp. 70-86). Westport, CT: Greenwood Press.

Johnson, C. L. (2000). Perspectives on American kinship in the later 1990s. Journal of Marriage and the Family, 62, 623-639.

Knoester, C., Haynie, D. L., \& Stephens, C. M. (2006). Parenting practices and adolescents' friendship networks. Journal of Marriage \& Family, 68, 1247-1260.

La Greca, A. M., \& Lopez, N. (1998). Social anxiety among adolescents: Linkages with peer relations and friendships. Journal of Abnormal Child Psychology, 26, 83-94.

Ladd, G. W., Kochendehfer, B. J., \& Coleman, C. C. (1996). Friendship quality as a predictor of young children’s early school adjustment. Child Development, 67, 1103-1118.

Lareau, A. (2000). My wife can tell me who I know: Methodological and conceptual problems in studying fathers. Qualitative Sociology, 23, 407-433.

Malcolm, K. T., Jensen-Campbell, L. A., Rex-Lear, M., \& Waldrip, A. M. (2006). Divided we fall: Children's friendships and peer victimization. Journal of Social and Personal Relationships, 23, 721-740.

Meurling, C. N., Ray, G. E., \& LoBello, S. G. (1999). Children’s evaluations of classroom friend and classroom best friend relationships. Child Study Journal, 29, 79-96.

Neckerman, H. J. (1996). The stability of social groups in childhood and adolescence: The role of the classroom social environment. Social Development, 5, 131-145.

Parke, R. D., \& Ladd, G. W. (1992). Family-peer relationships: Modes of jinkage. Hillsdale, NJ: Erlbaum.

Parker, J. G., \& Asher, S. R. (1993). Friendship and friendship quality in middle childhood: Links with peer group acceptance and feelings of loneliness and social dissatisfaction.

Development

Psychology, 29, 611-621.

Raudenbush, S. W., \& Bryk, A. S. (2002). Hierarchical linear models: Applications and data analysis methods (2nd ed.). London: Sage Publications.

Rubin, K. H., Bukowski, W., \& Parker, J. G. (1998). Peer interactions, relationships, and groups. In N. Eisenberg (Ed.), Handbook of child psychology (5th ed., Vol. 3, pp. 619-700). New York: Wiley. 
Schneider, B. H.,Woodburn, S., del Pilar Soteras del Toro, M., \& Udvari, S. J. (2005). Cultural and gender differences in the implications of competition for early adolescent relationships. Merrill-Palmer Quarterly, 51, 163-191.

Tate, R. (2004). Interpreting hierarchical linear and hierarchical generalized linear models with slopes as outcomes. The Journal of Experimental Education, 73, 71-95. 